\title{
Analysis on rural household energy consumption in Hebei province
}

\author{
Gao Bo ${ }^{1, a}$, YUAN Honglin ${ }^{2, b}$, Geng Liwei ${ }^{1, c}$,Tang Juan ${ }^{1, d}$ \\ ${ }^{1}$ Mechanical and Electrical College, Agricultural University of Hebei, Baoding, Hebei, PRC \\ ${ }^{2}$ Science and Technology Dept., Hebei Scientific and Technical College, Baoding, Hebei, PRC

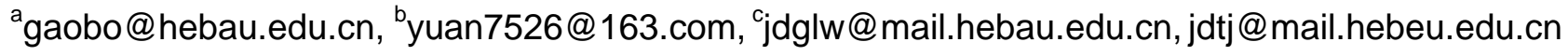

Keywords: rural household, energy consumption, survey.

Abstract. This paper summarizes the main findings regarding rural household energy consumption from 5130 households covering 171 counties in Hebei province. The results of the survey document behaviors of rural residents: the most commonly used fuel for heating is coal product (including honeycomb briquette and coal briquette), representing $70 \%$ or more of all heating at an average of $1502.23 \mathrm{kWh}$ per family; nearly $94.5 \%$ of all residents consume 101 to $5000 \mathrm{kWh}$ of electricity per year. $85.27 \%$ of all respondents concern electricity consumption but their opinions on electricity-saving appliances take on diversity. To change the high-pollution and low-efficiency way of energy use need economic- social development in rural region construction.

\section{Introduction}

Being around the capital of China, Hebei province raised public concern about air quality and created enormous pressure to change the high air pollution outlook. Furthermore, Fog and Haze, has been become an overwhelming context in environmental protection and sustainable development scenario instead of air pollution, conceptual norm in northern region of China. "Beauty countryside" program aimed to rebuild a natural and healthy rural living circumstance and keep balance with rural and urban social-economic development.

\section{Research reviews}

Associated with economic growth, environmental problems, such as Climate change, water pollution and shortages, a loss of biodiversity and other forms of environmental degradation are threatening the lives of people. Many research results have given academic explanations of Chemical Characteristics of PM2.5 and PM10 in Haze-Fog Episodes in Beijing[1], the formation of fog and haze in North China Plain[2] and its multiple pollution sources[3]. Cultural and Social influences co-exist with economic and legal instruments as part of the institutions governing the mitigation of diffuse pollution and climate change [4]. The social-structural factors and socialization experiences through which people form their environmental values, attitudes, and behaviors are the keys to analyze and predict pro-environmental behaviors of residents living in rural or urban areas[5-7].

A considerable amount of research have been carried on the characteristics of residential energy consumption in China: as a result of household consumption survey in 26 Chinese provinces in 2012, the typical Chinese household consumed 1426 kilograms standard coal equivalent which includes space heating, cooking, and water heating as three major end-use activities by district heating, natural gas, and electricity as three major residential energy sources. But, firewood is still the dominant fuel consumed in rural household energy consumption [8]. In rural areas of northeast region, fossil fuel including firewood, crop straws, and coal, is still occupied a majority place in rural household energy consumption, while cooking, heating, and drinking took on $90 \%$ of total energy consumption in rural household. 


\section{Methodology}

This paper examines the results from a public survey conducted as part of a study on rural household living condition and environment in Hebei province in 2014 summer and 2015 spring. This paper aims to draw lessons from the pilots to understand the determinants of current energy use patterns, causes for variations, design appropriate methodologies to measure the impacts of these factors, and most importantly, to arrive at useful policy recommendations. From the sampling frame, a total of 5130 were administered. With regard to energy administrators, a total of 513 village chiefs and 171 heads of related competent departments were interviewed. The main background information is given in Table 1.

Table 1 Background information of respondents

\begin{tabular}{|c|c|c|c|c|c|}
\hline & Category & $\begin{array}{c}\text { Share in survey } \\
{[\%]}\end{array}$ & & Category & $\begin{array}{c}\text { Share in survey } \\
{[\%]}\end{array}$ \\
\hline \multirow{3}{*}{ Gender } & Male & $73.25 \%$ & \multirow{6}{*}{$\begin{array}{l}\text { Family } \\
\text { population }\end{array}$} & $1-2$ & $14.80 \%$ \\
\hline & Female & $23.28 \%$ & & $3-5$ & $65.38 \%$ \\
\hline & $18-39$ & $42.04 \%$ & & 6\&over & $19.82 \%$ \\
\hline \multirow[t]{3}{*}{ Age } & $40-59$ & $34.20 \%$ & & Planting & $47.19 \%$ \\
\hline & 60\&over & $23.76 \%$ & & Breeding & $3.10 \%$ \\
\hline & Unschooled & $4.43 \%$ & & Foresting & $3.51 \%$ \\
\hline \multirow[t]{4}{*}{ education } & Elementary school & $22.62 \%$ & \multirow[t]{4}{*}{ occupation } & Aquaculture & $1.21 \%$ \\
\hline & Middle school & $49.63 \%$ & & Business & $5.98 \%$ \\
\hline & High school & $16.60 \%$ & & Labor work & $18.91 \%$ \\
\hline & College \& above & $6.51 \%$ & & others & $9.97 \%$ \\
\hline
\end{tabular}

As shown in Table1, current rural family structures and interviewees' personal information is clearly to help us understand their choices and behaviors on energy consumption.

\section{Main results of survey}

Energy structure in rural families. Energy-using in rural living mainly includes heating, cooking, lighting, bathing, cleanliness, and others. So the sources of energy for rural living are depended on diet, living habit and the local availability of commercial energy. After the pilot survey, we defined seven types of energy as honeycomb briquette, coal briquette, solar power, biogas, electricity, firewood and others.

For the choice of heating energies, all respondents are divided into two groups: single choice for energy source ( shared $14.4 \%$ of the total respondents) and multiple choices of energies(shared $85.6 \%$ of the total respondents). There is a similar structure in the two groups: the vast of majority of heating energy is coal briquette (shared more than $60 \%$ in each of the two groups) and next is honeycomb briquette (10\% or so). That means coal is the first choice of heating in rural family (nearly $80 \%$ ) and firewood or straw is the second choice of energy materials (nearly 10\%). The usage of "clean energy" just occupies a lower share.

Main types of energy consumption in rural families. As the respondents' self-descripted results, the annual energy consumption of every group is shown in Table 2.

For the first subset $(0-100 \mathrm{kWh})$, we can infer that such $4 \%$ rural residents do not own a refrigerator or air conditioner at home. Furthermore, annual power consumption can be worked as an index to target needy families. 
Table 2 The annual power consumptions per family

\begin{tabular}{rr}
\hline Annual power consumption[kWh] & \multicolumn{1}{c}{ Share } \\
\hline $0-100$ & $4.04 \%$ \\
$101-1000$ & $35.36 \%$ \\
$1001-5000$ & $59.58 \%$ \\
$>5000$ & $1.01 \%$ \\
Mean of annual power consumption & 1502.23 \\
\hline
\end{tabular}

In rural region, coal is the primary source of energy for heating in winter. Without district heating supply system, independent heating need easy and inexpensive applicants including energy cost. The average of annual coal consumption is 2.14 tons and $80 \%$ respondents consume 1-3 tons of coal per year for heating. The distribution of coal use is given in Fig. 1.

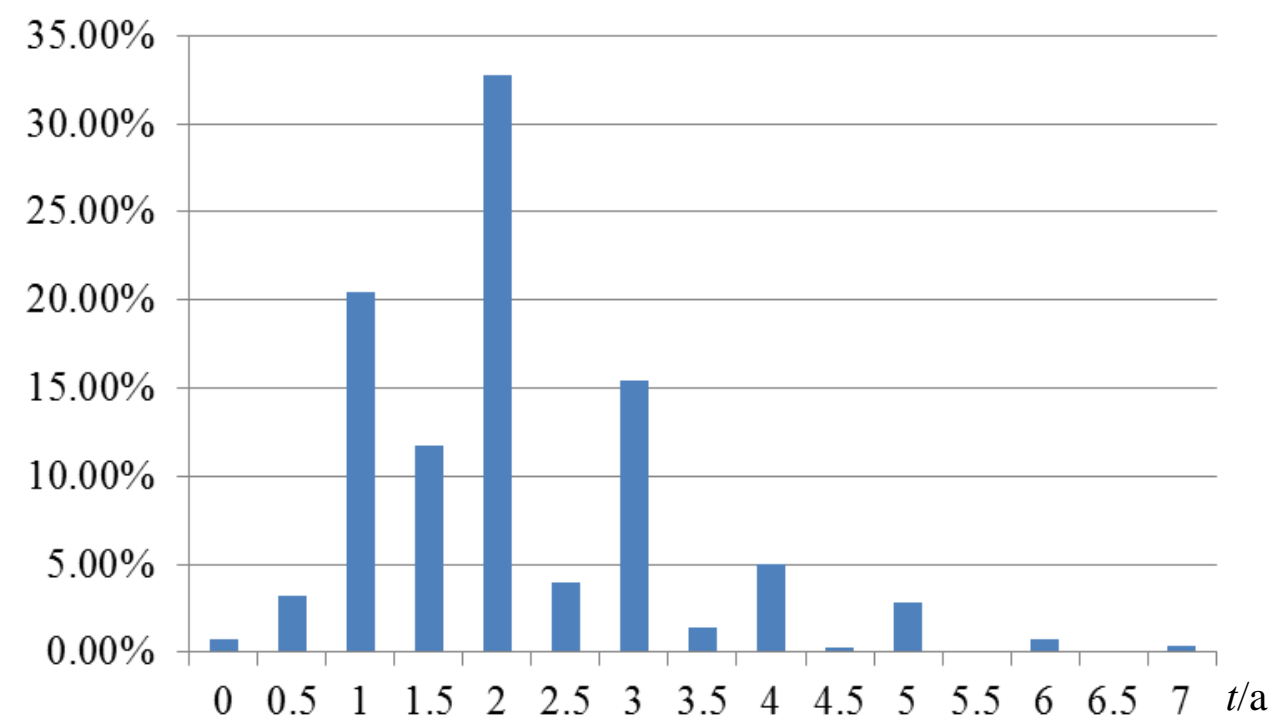

Fig. 1 The share of coal annual consumption in heating

The attitudes of energy saving in rural families. Almost $85.27 \%$ respondents said they concerned the power consumption of electrical applicants but a contradictory views exists on energy-saving products: $28.12 \%$ of residents considered energy-saving products have an evident electricity-saving effect; nearly half $(48.58 \%)$ of respondents had a contradictory view; all others respected the effect of power saving but cannot accept the higher price of energy -saving products. The underlying cause of the attitudes of energy-saving products is the family income which can be reflected by the attitude of the power bill. Seldom respondents think the impact on electricity rates exist but nearly half $(57.78 \%)$ considered the power bill has a modest influence of their lives while $23.67 \%$ think the power bills have a serious impact on life.

\section{Conclusions}

Most rural families choose multiple sources of energy which can lead to a more reasonable and economic choice to meet the satisfaction of rural living but coal occupies quite majority of the energy for home heating. Because of such insufficiency and high-pollution ways of heating, air pollution increased and local air quality has deteriorated in heating quarters.

In contrast, electricity is a kind of clean energy and it takes on more flexible on consumption. Generally, respondents concerned the electricity consumption and the bill of power but hesitated to choose a power-saving applicant because of its uncertain cost/ energy saving performance.

Based on the above views, the fundamental solutions to construct "beautiful countryside" project are to change the living style of rural families with the aid of poverty alleviation programs or urbanization. 


\section{Acknowledgements}

This work was financially supported by "The development of social science research project in Hebei province- Analysis on the structure of rural household energy consumption in Hebei"(No. 2015031220), partially supported by "The development of social science research project in Hebei province"(No 201602120103) and "The development of science and technology project in Baoding city"(No. 15zn006).

\section{References}

[1] Yele Sun, Guoshun Zhuang, Aohan Tang, Ying Wang, and Zhisheng An: Chemical Characteristics of PM2.5 and PM10 in Haze-Fog Episodes in Beijing.Environmental Science and Technology, Vol. 40(2006), p. 3148-3155.

[2] J. Quan, Q. Zhang, H. He, J. Liu, M. Huang, and H. Jin: Analysis of the formation of fog and haze in North China Plain (NCP). Atmospheric Chemistry and Physics, Vol.11(2011), p. 8205-8214.

[3] Xin Ling:Tracking down China's Haze Pollution.Bulletin of the Chinese Academy of Sciences,Vol. 27(2013), p. 140-144.

[4] K.L. Blackstock, J. Ingram, R. Burton, K.M. Brown, and B. Slee: Understanding and influencing behavior change to improve water quality. Science of the Total Environment, Vol. 408(2010), p.5631-5638.

[5] Jaime Berenquer, JoséA. Corraliza, and Rocío Martin: Rural-Urban Differences in Environmental Concern, Attitudes, and Actions. European Journal of Psychological Assessment, Vol. 21(2011),p. 128-138.

[6] Axelrod, Lawrence J. and Lehman Darrin R: Responding to Environmental Concerns: What Factors Guide Individual Action.Journal of Environmental psychology, Vol.13(1993),p. 149-159.

[7] Chan, Kam Wang and Li Zhang: The Hukou System and Rural-urban Migration in China: Processes and changes. The China Quarterly, Vol. 160(1999),p.818-855.

[8] Xinye Zheng, Chu Wei, and Ping Qin: Characteristics of Residential Energy Consumption in China: Findings from a Household Survey. Energy Policy, 75(2014),p.126-135. 